\title{
OPTIMASI BIAYA PEMELIHARAAN
}

\author{
Hardiman ${ }^{1}$, Manyuk Fauzi ${ }^{2}$, Imam Suprayogi ${ }^{3}$ \\ 1,2,3]urusan Teknik Sipil, Fakultas Teknik, Universitas Riau \\ Email: hardiman.hardiman@grad.unri.ac.id (korespondensi)
}

\begin{abstract}
The performance of the irrigation system management in Riau Province has not shown an optimal irrigation management function and irrigation conditions and functions due to budget constraints that have an impact on the performance of one of the irrigation areas in this province, namely the Uwai irrigation area. The purpose of this research is to get the performance value of the irrigation network system in the Uwai irrigation area and get budget optimization in the Uwai irrigation area. The results showed that the greatest assessment of damage to physical conditions in the Uwai irrigation network was found in the carrier channel $R U$ 4, RU 5, RU 6, RU 7 left, which was $40 \%$ of the total channels and buildings and the smallest functional condition assessment in the Uwai irrigation network. found on channel $R U$ 4, RU 5, $R U 6, R U 7$ left, which is $75 \%$ so that this channel is only able to serve $85.5 \mathrm{Ha}$ from $342 \mathrm{Ha}$, $71 \mathrm{Ha}$ from $284 \mathrm{Ha}, 59.5 \mathrm{Ha}$ from $238 \mathrm{Ha}, 36.75 \mathrm{Ha}$ of $147 \mathrm{Ha}$ to be served.
\end{abstract}

Keywords: Irrigation, Infrastructure Performance

\begin{abstract}
Abstrak
Kinerja Pengelolaan sistem irigasi Provinsi Riau belum menunjukkan fungsi manajemen irigasi dan kondisi serta fungsi irigasi yang optimal akibat adanya keterbatasan anggaran yang ada sehingga berdampak pada kinerja salah satu daerah irigasi di provinsi ini yaitu daerah irigasi Uwai. Tujuan dari penelitian ini adalah untuk mendapat nilai kinerja sistem jaringan irigasi pada daerah irigasi Uwai dan mendapat optimalisasi anggaran pada daerah irigasi Uwai. Hasil penelitian menunjukkan Penilaian kerusakan kondisi fisik di jaringan irigasi Uwai paling besar terdapat pada saluran pembawa $R U$ 4, $R U$ 5, $R U$ 6, $R U 7$ kiri, yaitu sebesar $40 \%$ dari keseluruhan saluran dan bangunan dan penilaian kondisi fungsional di jaringan irigasi Uwai yang paling kecil terdapat pada saluran $R U$ 4, $R U 5, R U 6, R U 7$ kiri yaitu sebesar $75 \%$ sehingga pada saluran ini hanya mampu melayani 85.5 Ha dari $342 \mathrm{Ha}, 71 \mathrm{Ha}$ dari $284 \mathrm{Ha}, 59,5 \mathrm{Ha}$ dari $238 \mathrm{Ha}, 36,75 \mathrm{Ha}$ dari $147 \mathrm{Ha}$ yang harus dilayani.
\end{abstract}

Kata kunci: Irigasi, Kinerja Prasarana

\section{PENDAHULUAN}

\subsection{Latar Beakang}

Penetapan sistem pengelolaan irigasi termasuk jaringan dan bangunan pelengkapnya dilaksanakan dengan memperhatikan secara teknis kondisi topografi, tata guna lahan, tata letak outlet, dan jaringan (Fauzi, dkk, 2015). Kondisi umum pengelolaan sistem irigasi di Indonesia menurut Kementerian Pekerjaan Umum dan Perumahan Rakyat pada Program Pengembangan dan Pengeloaan Sistem Irigasi di Indonesia (2018) khususnya yang terkait dengan kinerja jaringan irigasi, tergambarkan melalui hasil audit kinerja jaringan irigasi hingga tahun 2014 yang menunjukkan belum optimalnya manajemen irigasi dan kondisi serta fungsi prasarana irigasi permukaan nasional. Belum optimalnya manajemen irigasi terlihat dari belum efisiennya penggunaan air irigasi.

Berdasarkan luasan total irigasi permukaan di Indonesia seluas 7,10 juta ha atau $78,00 \%$ dari total luas irigasi nasional seluas 9,136 juta ha diperoleh infromasi bahwa seluas $46,00 \%$ atau sekitar 3,3 juta ha prasarana irigasi dalam kondisi rusak. Persentase prasarana irigasi dalam kondisi rusak sesuai kewenangannya maka 7,50\% merupakan kewenangan pusat, 8,26\% kewenangan provinsi dan 30,40\% kewenangan pemerintah kabupaten/kota.

Pelaksanaan operasi dan pemeliharaan daerah irigasi di Provinsi Riau mengenai pengaggaran dan pelaksanaan direncanakan setiap tahun. Besarnya anggaran sesuai yang tertuang dalam Dokumen Pelaksanaan Anggaran (DPA) Provinsi Riau hingga tahun anggaran 2017 tidak sesuai dengan 
kebutuhan nyata (riil). Sementara itu, daerah irigasi Uwai memiliki luasan $1.029 \mathrm{Ha}$ dan menjadi kewenangan pemerintah Provinsi Riau. Dengan keterbatasan anggaran yang ada, maka berdampak pada kinerja sistem irigasi Uwai Pangoan

\subsection{Tujuan Penelitian}

Tujuan dari penelitian ini adalah sebagai berikut:

1. Mendapat nilai kinerja sistem jaringan irigasi pada daerah irigasi Uwai

2. Mendapat optimalisasi anggaran pada daerah irigasi Uwai

\subsection{Batasan Masalah} adalah :

Batasan masalah dalam peneilitian ini

1. Biaya operasi dan pemeliharaan merupakan data yang sudah ada atau data sekunder yang diperoleh dari intansi yang berwenang dalam hal ini Dinas Pekerjaan Umum dan Penataan Ruang Provinsi Riau.

2. Biaya pemeliharaan yang dimaksud dalam penelitian ini meliputi biaya pemeliharaan rutin dan biaya pemeliharaan berkala, atau dengan kata lain tidak memasukkan biaya pemeliharaan darurat.

\section{Tinjauan Pustaka}

\subsection{Irigasi}

Menurut Peraturan Menteri Pekerjaan Umum dan Perumahan Rakyat Nomor 12/PRT/M/2015 irigasi merupakan usaha penyediaan, pengaturan, dan pembuangan air irigasi untuk menunjang pertanian yang jenisnya meliputi irigasi permukaan, irigasi rawa, irigasi air bawah tanah, irigasi pompa, dan irigasi tambak. Kesatuan lahan yang mendapat air dari satu jaringan irigasi disebut daerah irigasi. Sementara itu pengertian tentang sistem irigasi adalah meliputi prasarana irigasi, air irigasi, manajemen irigasi, kelembagaan pengelolaan irigasi, dan sumber daya manusia. Guna menjamin keberlangsungan fungsi sistem irigasi maka perlu dilakukan usaha-usaha pengelolaan aset irigasi. Pengelolaan aset irigasi merupakan proses manajemen yang terstruktur untuk perencanaan, pemeliharaan dan pendanaan sistem irigasi guna mencapai tingkat pelayanan yang ditetapkan dan berkelanjutan bagi pemakai air irigasi dan pengguna jaringan irigasi dengan pengelolaan aset irigasi seefisien mungkin
(PP Nomor 20 tahun 2006).

Aset Irigasi adalah jaringan irigasi dan pendukung pengelolaan irigasi. Pengertian tentang jaringan irigasi adalah saluran, bangunan, dan bangunan pelengkapnya yang merupakan satu kesatuan yang diperlukan guna penyediaan, pembagian, pemberian, penggunaan, dan pembuangan air irigasi. Adapun jaringan irigasi tersier adalah jaringan irigasi yang berfungsi sebagai prasarana pelayanan air irigasi dalam petak tersier yang terdiri dari saluran tersier, saluran kuarter dan saluran pembuang, boks tersier, boks kuarter serta bangunan pelengkapnya

\subsection{Indeks Kinerja}

Evaluasi indeks kinerja sistem irigasi dimaksudkan untuk mengetahui kondisi kinerja sistem irigasi yang meliputi : a). Prasarana fisik; b). Produktivitas tanaman; c). Sarana penunjang; d). Organisasi personalia; e). Dokumentasi dan f). Kondisi kelembagaan P3A. Komponen-komponen evaluasi tersebut tecantum dalam Peraturan Menteri PUPR No. 12/PRT/M/2015 tentang Eksploitasi dan Pemeliharaan Jaringan Irigasi. Menurut Tri Rahajeng (2011), bahwa penilaian kinerja sistem irigasi sebaiknya dilakukan setiap tahun agar dapat diketahui nilai kinerja sistem irigasi masing-masing daerah irigasi. Nilai yang diperoleh digunakan untuk menyusun program tindak lanjut seperti perbaikan berat, rehabilitasi serta operasi dan pemeliharaan jaringan irigasi yang lebih terarah dan tepat guna. Kriteria hasil penilaian indeks kinerja sistem irigasi sebagaimana Tabel 2.3. berikut ini.

Tabel 1 Kriteria Indeks Kinerja

\begin{tabular}{|c|c|c|}
\hline No. & Nilai & Kriteria \\
\hline 1 & $80-100$ & Kinerja sangat baik \\
\hline \multirow[t]{2}{*}{2} & $70-79$ & Kinerja baik \\
\hline & & $\begin{array}{c}\text { Kinerja kurang dan } \\
\text { perlu }\end{array}$ \\
\hline \multirow[t]{2}{*}{3} & $55-69$ & perhatian \\
\hline & & $\begin{array}{c}\text { Kinerja jelek dan } \\
\text { perlu }\end{array}$ \\
\hline 4 & $<55$ & perhatian \\
\hline
\end{tabular}

Sedangkan untuk penilaian kondisi fisik jaringan disesuaikan dengan indeks kinerja sistem irigasi (IKSI) menyangkut jumlah, dimensi, jenis dan keadaan fisik suatu jaringan irigasi. Kondisi fisik infrastruktur jaringan irigasi dapat diklasifikasikan sebagaimana Tabel 2.2 
Tabel 2 Klasifikasi Kondisi Fisik Infrastruktur Jaringan Irigasi

\begin{tabular}{clc}
\hline No. & $\begin{array}{l}\text { Kondisi Fisik } \\
\text { Infrastruktur }\end{array}$ & Kriteria \\
\hline \multirow{2}{*}{$\begin{array}{ll}\text { Tingkat kerusakan }< \\
10 \%\end{array}$} & Baik \\
& $\begin{array}{l}\text { Tingkat kerusakan } \\
2\end{array}$ & Rusak \\
& $\begin{array}{l}\text { Tingkat kerusakan } \\
21 \%-20 \%\end{array}$ & Ringan \\
3 & $\begin{array}{l}\text { Rusak } \\
\text { Tingkat kerusakan } \\
4\end{array}$ & Sedang \\
& $>40 \%$ & Rusak Berat
\end{tabular}

Tabel di atas merupakan salah satu penjelasan tentang indikator keberhasilan kegiatan pemeliharaan. Indikator-indikator keberhasilan tersebut meliputi:

1. Terpenuhinya kapasitas saluran sesuai dengan kapasitas rencana.

2. Terjaganya kondisi bangunan dan saluran:

a) Kondisi baik jika tingkat kerusakan $<10 \%$ dari kondisi awal bangunan dan saluran, diperlukan pemeliharaan rutin.

b) Kondisi rusak ringan jika tingkat kerusakan 10 - $20 \%$ dari kondisi awal bangunan dan saluran, diperlukan pemeliharaan berkala yang bersifat perawatan.

c) Kondisi rusak sedang jika tingkat kerusakan 21 - $40 \%$ dari kondisi awal bangunan dan saluran, diperlukan pemeliharaan berkala yang bersifat perbaikan.

d) Kondisi rusak berat jika tingkat kerusakan > $40 \%$ dari kondisi awal bangunan dan saluran, diperlukan pemeliharaan berkala yang bersifat perbaikan berat atau penggantian.

3. Meminimalkan biaya rehabilitasi jaringan irigasi.

4. Tercapainya umur rencana jaringan irigasi

\subsection{Linear Programming}

Metode pemograman linier pertama kali ditemukan oleh ahli statistika Amerika Serikat yang bernama Prof. George Dantzig (Father of the Linear Programming). Pemograman Linier disingkat PL merupakan metode matematik dalam mengalokasikan sumber daya yang terbatas untuk mencapai suatu tujuan seperti memaksimumkan keuntungan dan meminimumkan biaya. PL banyak diterapkan dalam masalah ekonomi, industri, militer, sosial dan lain-lain. PL berkaitan dengan penjelasan suatu kasus dalam dunia nyata sebagai suatu modal matematik yang terdiri dari sebuah fungsi tujuan linier dengan beberapa kendala linier.

\section{Metodologi Penelitian}

\subsection{Lokasi Penelitian}

Lokasi Penelitian dilakukan di Daerah Irigasi Uwai di Desa Uwai, Kecamatan Bangkinang Seberang Kecamatan Salo, Kabupaten Kampar, Provinsi Riau. Secara geografis Daerah Irigasi Uwai terletak pada $0^{\circ} 15^{\prime} \mathrm{LU}, 0^{\circ} 5^{\prime} \mathrm{BS}, 103^{\circ} 48^{\prime} \mathrm{BB}, 10^{\circ} 10^{\prime} \mathrm{BT}$.

\subsection{Studi Literatur}

Sebagai bahan penunjang dalam penelitian ini maka dilakukan studi literatur yang berhubungan dengan hal-hal sebagai berikut :

1. Pemeliharaan jaringan irigasi;

2. Nilai kondisi fisik dan nilai fungsi jaringan irigasi;

3. Model linier programming

\subsection{Pengumpulan Data}

Pengumpulan data sekunder dilakukan secara survey instansi dalam bentuk laporanlaporan yang terkait dengan topik penelitian. Data sekunder diperoleh dari Balai Wilayah Sungai Sumatera III Jl. Cut Nyak Dien Pekanbaru, Dinas Pekerjaan Umum dan Penataan Ruang Provinsi Riau Jl. SM. Amin Pekanbaru dan PUPR Kabupaten Kampar Jl. HR. Subrantas 101 Bangkinang, sedangkan data primer diperoleh dari pengamatan langsung di lapangan

\section{Hasil dan Pembahasan}

\subsection{Penelusuran dan Inventarisasi Aset Jaringan Irigasi}

Berikut ditampilkan hasil penelusuran dan inventarisasi bangunan utama (bendung) ditampilkan pada Tabel 3.

Tabel 3 Data Teknis Bendung Uwai

\begin{tabular}{lcr}
\hline \multicolumn{1}{c}{ Uraian } & Unit & Besaran \\
\hline B $_{\text {eff weir }}$ & $\mathrm{m}$ & 7,20 \\
\hline $\mathrm{H}_{\text {weir }}$ & $\mathrm{m}$ & 3,10 \\
\hline $\mathrm{B}_{\text {pilar }}$ & $\mathrm{m}$ & 0,90 \\
\hline$\square$ Pilar & $\mathrm{bh}$ & 3,00 \\
\hline$B_{\text {pintu flushing }}$ & $\mathrm{m}$ & 1,80 \\
\hline$\square$ Pintu flushing & $\mathrm{bh}$ & 2,00 \\
\hline Lhilir & $\mathrm{m}$ & 9,00 \\
\hline$\square$ Pintu intake & bh & 2,00 \\
\hline
\end{tabular}




\begin{tabular}{lcr}
\hline \multicolumn{1}{c}{ Uraian } & Unit & Besaran \\
\hline B $_{\text {pintu intake kanan }}$ & $\mathrm{m}$ & 0,70 \\
\hline B $_{\text {pintu intake kiri }}$ & $\mathrm{m}$ & 1,00 \\
\hline
\end{tabular}

Ket : Dibangun tahun 1942

Tipe bendung : fix dam (tipe ogee) tanpa kantong lumpur

Tipe lantai hilir : tanpa peredam energi

\subsection{Lokasi Daerah Kajian}

Berdasarkan data inventaris Daerah Irigasi Uwai untuk saluran pembawa (saluran primer dan saluran sekunder) mencapai 4.605 meter, sedangkan total jumlah bangunan 44 buah. Skema jaringan irigasi pada daerah irigasi Uwai. Data sarana prasarana jaringan irigasi daerah irigasi Uwai dari hasil inventarisasi yang dinilai kinerjanya ditunjukkan pada Tabel 4 terlampir.

Luas masing-masing petak sawah pada daerah irigasi Uwai dapat dilihat pada skema di atas dan dirangkum pada Tabel 5 dibawah ini :

Tabel 5 Luas Petak Tersier

\begin{tabular}{ccc} 
No & Nama Ruas & Luas (Ha) \\
\hline 1 & Bendung Uwai & 1139 \\
\hline 2 & RU 1 KA & 203 \\
\hline 3 & RU 2 KA & 170 \\
\hline 4 & RU 3 KA & 150 \\
\hline 5 & RU 4 KA & 133 \\
\hline 6 & RU 5 KA & 82 \\
\hline 7 & RU 1 KI & 936 \\
\hline 8 & RU 2 KI & 793 \\
\hline 9 & RU 3 KI & 607 \\
\hline 10 & RU 4 KI & 342 \\
\hline 11 & RU 5 KI & 284 \\
\hline 12 & RU 6 KI & 238 \\
\hline 13 & RU 7 KI & 147 \\
\hline 14 & BU 1 KA & 203 \\
\hline 15 & BU 2 KA & 170 \\
\hline 16 & BU 3 KA & 133 \\
\hline 17 & BU 4 KA & 133 \\
\hline 18 & BU 1 KI & 936 \\
\hline 19 & BU 2 KI & 793 \\
\hline 20 & BU 3 KI & 607 \\
\hline 21 & BU 4 KI & 342 \\
\hline 23 & BU 5 KI & 284 \\
\hline 24 & BU 6 KI & 238 \\
\hline BU 7 KI & 147
\end{tabular}

Sumber: Dinas PUPR Provinsi Riau

\subsection{Kondisi Fisik Jaringan Irigasi Uwai}

Jaringan irigasi Uwai tidak semuanya dalam kondisi baik, beberapa ruas tertentu mengalami kerusakan dengan tingkat kerusakan yang beragam. Hasil pengamatan langsung ke lapangan dimana penilaiannya berpedoman kepada IKSI dan Permen PU No.12/PRT/M/2012 dengan ciri fisik yang telah dikembangkan ditemukan tingkat Kerusakan prasarana fisik pada jaringan irigasi Uwai seperti yang tersaji pada pada Tabel 6 di bawah ini :

Tabel 6 Kerusakan prasarana fisik pada jaringan irigasi Uwai

\begin{tabular}{|c|c|c|c|}
\hline No & Uraian & $\begin{array}{c}\text { Kerusaka } \\
\text { n Fisik } \\
\text { Aset }(\%)\end{array}$ & Kriteria \\
\hline 1 & Bendung Uwai & 12,5 & Rusak Ringan \\
\hline 2 & RU $1 \mathrm{KA}$ & 10 & Baik \\
\hline 3 & RU 2 KA & 20 & Rusak Ringan \\
\hline 4 & RU $3 \mathrm{KA}$ & 30 & Rusak Sedang \\
\hline 5 & RU 4 KA & 20 & Rusak Ringan \\
\hline 6 & RU 5 KA & 10 & Baik \\
\hline 7 & RU $1 \mathrm{KI}$ & 20 & Rusak Ringan \\
\hline 8 & RU $2 \mathrm{KI}$ & 20 & Rusak Ringan \\
\hline 9 & RU $3 \mathrm{KI}$ & 25 & Rusak Sedang \\
\hline 10 & RU $4 \mathrm{KI}$ & 40 & Rusak Sedang \\
\hline 11 & RU $5 \mathrm{KI}$ & 40 & Rusak Sedang \\
\hline 12 & RU $6 \mathrm{KI}$ & 40 & Rusak Sedang \\
\hline 13 & RU $7 \mathrm{KI}$ & 40 & Rusak Sedang \\
\hline 14 & $\mathrm{BU} 1 \mathrm{KA}$ & 10 & Baik \\
\hline 15 & BU $2 \mathrm{KA}$ & 15 & Rusak Ringan \\
\hline 16 & $\mathrm{BU} 3 \mathrm{KA}$ & 15 & Rusak Ringan \\
\hline 17 & $\mathrm{BU} 4 \mathrm{KA}$ & 30 & Rusak Sedang \\
\hline 18 & $\mathrm{BU} 1 \mathrm{KI}$ & 10 & Baik \\
\hline 19 & $\mathrm{BU} 2 \mathrm{KI}$ & 10 & Baik \\
\hline 20 & $\mathrm{BU} 3 \mathrm{KI}$ & 10 & Baik \\
\hline 21 & $\mathrm{BU} 4 \mathrm{KI}$ & 10 & Baik \\
\hline 22 & BU $5 \mathrm{KI}$ & 30 & Rusak Sedang \\
\hline 23 & $\mathrm{BU} 6 \mathrm{KI}$ & 35 & Rusak Sedang \\
\hline 24 & $\mathrm{BU} 7 \mathrm{KI}$ & 35 & Rusak Sedang \\
\hline
\end{tabular}

\subsection{Kondisi Fungsional Jaringan Irigasi Uwai}

Penilaian kondisi fungsional jaringan irigasi ini berpedomankan pada tabel IKSI dengan melihat ciri-ciri kondisi fungsional yang dikembangkan berdasarkan Permen PU No.12/PRT/M/2012 dengan cara pengamatan langsung ke lokasi dan melakukan sesi wawancara dengan pihak-pihak yang terlibat. Penilaian fungsional dari prasarana fisik jaringan irigasi dapat dilihat pada Tabel 7 (terlampir)

Berdasarkan tabel 7 dapat dilihat bahwa salah satu kerusakan yang mempengaruhi air sampai ke daerah layanan adalah kerusakan pada saluran pembawa (RU $1 \mathrm{KA}$ ) dimana sebanyak 20,3 Ha tidak terlayani dari total $203 \mathrm{Ha}$ yang harus dilayani.

\subsection{Urutan Prioritas Pemeliharaan Kerusakan Jaringan Uwai}

Rekapitulasi perhitungan nilai prioritas dan urutan prioritas pemeliharaan jaringan irigasi Uwai dapat dilihat pada tabel 8 di bawah ini:

Tabel 8 Nilai dan Urutan Prioritas Pemeliharaan 


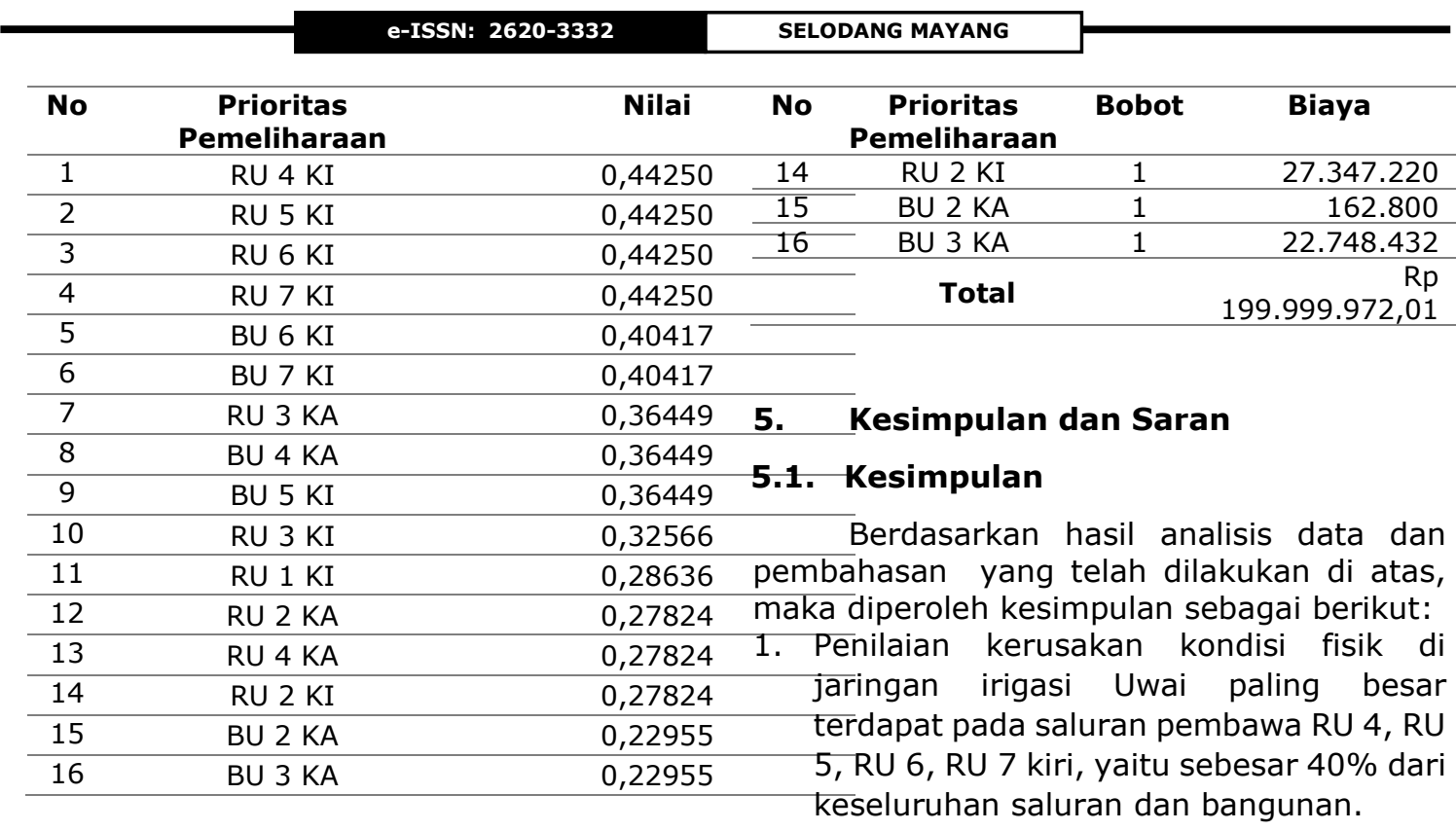

\subsection{Biaya Pemeliharaan Jaringan Irigasi Uwai}

Apabila kondisi jaringan irigasi baik, maka air irigasi juga tetap tersedia untuk daerah layanan. Agar kondisi tiap saluran dan bangunan yang ada di jaringan irigasi tetap dalam keadaan baik, maka setiap jaringan irigasi tersebut harus dilakukan pemeliharaan. Tetapi, untuk kegiatan pemeliharaan tersebut dibutuhkan biaya yang tidak sedikit dimana total biaya keseluruhan yang diperlukan untuk kegiatan pemeliharaan pada DI Uwai Pangoan adalah sebesar Rp. 47.151.078-.

\subsection{Pemodelan Menggunakan Linier Programming}

Dengan anggaran biaya pemeliharaan sebesar Rp. 200,000,000 kemudian persamaan linier programming yang terdiri dari fungsi tujuan dan fungsi kendala dimasukan kedalam Software POM/QM for windows bisa dilihat pada gambar 9 berikut ini:

Tabel 9. Anggaran Biaya Pemeliharaan

\begin{tabular}{cccr}
\hline No & $\begin{array}{c}\text { Prioritas } \\
\text { Pemeliharaan }\end{array}$ & Bobot & \multicolumn{1}{l}{ Biaya } \\
\hline 1 & RU 4 KI & 1 & 77.202 .720 \\
\hline 2 & RU 5 KI & 1 & 11.419 .056 \\
\hline 3 & RU 6 KI & 1 & 4.461 .912 \\
\hline 4 & RU 7 KI & 1 & 6.228 .090 \\
\hline 5 & BU 6 KI & 1 & 162.800 \\
\hline 6 & BU 7 KI & 1 & 244.200 \\
\hline 7 & RU 3 KA & 1 & 11.008 .143 \\
\hline 8 & BU 4 KA & 1 & 162.800 \\
\hline 9 & BU 5 KI & 1 & 162.800 \\
\hline 10 & RU 3 KI & 1 & 19.407 .240 \\
\hline 11 & RU 1 KI & 1 & 8.031 .600 \\
\hline 12 & RU 2 KA & 1 & 3.662 .064 \\
\hline 13 & RU 4 KA & 1 & 7.582 .950 \\
\hline
\end{tabular}

2. Penilaian kondisi fungsional di jaringan irigasi Uwai yang paling kecil terdapat pada RU 4,5,6,7 kiri yaitu sebesar $75 \%$ sehingga pada saluran ini hanya mampu melayani $85.5 \mathrm{Ha}$ dari $342 \mathrm{Ha}, 71 \mathrm{Ha}$ dari $284 \mathrm{Ha}, 59,5 \mathrm{Ha}$ dari $238 \mathrm{Ha}, 36,75 \mathrm{Ha}$ dari $147 \mathrm{Ha}$ yang harus dilayani.

\subsection{Saran}

Berikut ini saran yang berikan berdasarkan hasil kajian dari penelitian ini., yaitu:

1. Menambah parameter investasi seperti nilai manfaat dan biaya (Benefit Cost Ratio) untuk melihat kelayakan dari kegiatan pemeliharaan yang akan dilakukan.

2. Menambahkan parameter fungsi kendala, dengan membuat kombinasi keterbatasan biaya yang beragam untuk melihat perbandingannya.

\section{DAFTAR PUSTAKA}

[1] Aurora Leoni, W., (2020). Optimasi Biaya Pemeliharaan Prasarana Fisik Jaringan Irigasi Sei.Paku.

[2] Departemen Pekerjaan Umum. (1986). Kriteria Perencanaan Jaringan Irigasi KP 01. $1-269$. birohukum.pu.go.id/uploads/DPU/2015/ PermenPUPR23-2015.pdf

[3] Fauzi, M., Sandhiyavitri, A., Sutikno, S., \& Suharyanto (2017). Penilaian Indeks Kinerja Daerah Irigasi Berdasarkan Peraturan Menteri PUPR Nomor 12 Tahun 
2015. Konferensi Nasional Teknik Sipil dan Infrastruktur - I

[4] Pekerjaan Umum, K. (2017). Permen PUPR 30/PRT/2007 tentang Pengembangan Dan Pengelolaan Sistem Irigasi. Kementerian Keuangan Republik Indonesia, 1, 1-25.

[5] Pekerjaan Umum, K. (2007). Permen PUPR 32/PRT/2007 tentang Pedoman Operasi Dan Pemeliharaan Jaringan Irigasi.

[6] Pekerjaan Umum, K. (2015). Permen PUPR 32/PRT/2007 tentang Eksploitasi Dan Pemeliharaan Jaringan Irigasi (Vol. 53, Issue 5).

[7] Tri Rahayu, I., (2020). Optimasi Biaya Pemeliharaan Jaringan Irigasi Daerah Seberang Gunung.

[8] Karnanda, E. J. (2016). Kajian optimalisasi lahan pertanian pada daerah irigasi sungai paku kecamatan kampar kiri kabupaten kampar. 1-15. 
Tabel 4. Kinerja Jaringan Irigasi Daerah Irigasi Uwai

\begin{tabular}{lccccccc}
\hline Bendung & Intake & \multicolumn{2}{c}{ Panjang Saluran } & \multicolumn{2}{c}{ Jumlah Bangunan (unit) } & $\begin{array}{c}\text { Luas Sawah } \\
(\mathrm{m})\end{array}$ & \multicolumn{2}{c}{ Ket. } \\
\cline { 3 - 8 } & & Primer & Sekunder & Pengukur & Pengatur & Pelengkap & \\
\hline \multirow{2}{*}{ Uwai } & Kanan & 450 & 1.165 & 0 & 9 & 1 & 203 \\
& Kiri & 600 & 3.554 & 0 & 19 & 15 & 704 \\
\hline
\end{tabular}

Tabel 7. Penilaian Fungsional Dari Prasarana Fisik Jaringan Irigasi

\begin{tabular}{|c|c|c|c|c|c|c|c|c|c|c|}
\hline \multirow{2}{*}{ No } & \multirow{2}{*}{ Uraian } & \multicolumn{4}{|c|}{ Air irigasi ke daerah layanan } & \multicolumn{2}{|c|}{ Penilaian fungsi } & \multirow[t]{2}{*}{$\begin{array}{c}\text { Luas } \\
\text { daerah } \\
\text { layanan }\end{array}$} & \multicolumn{2}{|c|}{$\begin{array}{c}\text { Luas Layanan Terpengaruh } \\
\text { Kerusakan }\end{array}$} \\
\hline & & $>80 \%$ & $\begin{array}{c}40 \%- \\
80 \%\end{array}$ & $\begin{array}{c}20 \%- \\
40 \%\end{array}$ & $<20 \%$ & $\%$ & Kriteria & & & \\
\hline 1 & $\begin{array}{c}\text { Bendung } \\
\text { Uwai }\end{array}$ & & & 20,00 & & 80,00 & Kurang & 1139 & 227,80 & Ha Tidak terlayani \\
\hline 2 & $\mathrm{RU} 1 \mathrm{KA}$ & & & & 10,00 & 90,00 & Baik & 203 & 20,30 & Ha Tidak terlayani \\
\hline 3 & RU 2 KA & & & & 15,00 & 85,00 & Baik & 170 & 25,50 & Ha Tidak terlayani \\
\hline 4 & RU $3 \mathrm{KA}$ & & & & 18,00 & 82,00 & Baik & 150 & 27,00 & Ha Tidak terlayani \\
\hline 5 & RU 4 KA & & & & 15,00 & 85,00 & Baik & 133 & 19,95 & Ha Tidak terlayani \\
\hline 6 & RU 5 KA & & & & 15,00 & 85,00 & Baik & 82 & 12,30 & Ha Tidak terlayani \\
\hline 7 & RU 1 KI & & & & 10,00 & 90,00 & Baik & 936 & 93,60 & Ha Tidak terlayani \\
\hline 8 & RU 2 KI & & & & 15,00 & 85,00 & Baik & 793 & 118,95 & Ha Tidak terlayani \\
\hline 9 & RU 3 KI & & & 20,00 & & 80,00 & Kurang & 607 & 121,40 & Ha Tidak terlayani \\
\hline 10 & RU 4 KI & & & 25,00 & & 75,00 & Kurang & 342 & 85,50 & Ha Tidak terlayani \\
\hline 11 & RU 5 KI & & & 25,00 & & 75,00 & Kurang & 284 & 71,00 & Ha Tidak terlayani \\
\hline 12 & RU 6 KI & & & 25,00 & & 75,00 & Kurang & 238 & 59,50 & Ha Tidak terlayani \\
\hline 13 & RU 7 KI & & & 25,00 & & 75,00 & Kurang & 147 & 36,75 & Ha Tidak terlayani \\
\hline 14 & $\mathrm{BU} 1 \mathrm{KA}$ & & & & 10,00 & 90,00 & Baik & 203 & 20,30 & Ha Tidak terlayani \\
\hline
\end{tabular}




\begin{tabular}{|c|c|c|c|c|c|c|c|c|c|c|}
\hline \multirow{2}{*}{ No } & \multirow{2}{*}{ Uraian } & \multicolumn{4}{|c|}{ Air irigasi ke daerah layanan } & \multicolumn{2}{|c|}{ Penilaian fungsi } & \multirow{2}{*}{$\begin{array}{c}\text { Luas } \\
\text { daerah } \\
\text { layanan }\end{array}$} & \multicolumn{2}{|c|}{$\begin{array}{c}\text { Luas Layanan Terpengaruh } \\
\text { Kerusakan }\end{array}$} \\
\hline & & $>80 \%$ & $\begin{array}{l}40 \%- \\
80 \%\end{array}$ & $\begin{array}{l}20 \%- \\
40 \%\end{array}$ & $<20 \%$ & $\%$ & Kriteria & & & \\
\hline 15 & $\mathrm{BU} 2 \mathrm{KA}$ & & & & 12,00 & 88,00 & Baik & 170 & 20,40 & Ha Tidak terlayani \\
\hline 16 & $\mathrm{BU} 3 \mathrm{KA}$ & & & & 12,00 & 88,00 & Baik & 133 & 15,96 & Ha Tidak terlayani \\
\hline 17 & $\mathrm{BU} 4 \mathrm{KA}$ & & & & 18,00 & 82,00 & Baik & 133 & 23,94 & Ha Tidak terlayani \\
\hline 18 & BU $1 \mathrm{KI}$ & & & & 10,00 & 90,00 & Baik & 936 & 93,60 & Ha Tidak terlayani \\
\hline 19 & BU 2 KI & & & & 10,00 & 90,00 & Baik & 793 & 79,30 & Ha Tidak terlayani \\
\hline 20 & BU 3 KI & & & & 10,00 & 90,00 & Baik & 607 & 60,70 & Ha Tidak terlayani \\
\hline 21 & $\mathrm{BU} 4 \mathrm{KI}$ & & & & 10,00 & 90,00 & Baik & 342 & 34,20 & Ha Tidak terlayani \\
\hline 22 & BU 5 KI & & & & 18,00 & 82,00 & Baik & 284 & 51,12 & Ha Tidak terlayani \\
\hline 23 & BU 6 KI & & & 22,00 & & 78,00 & Kurang & 238 & 52,36 & Ha Tidak terlayani \\
\hline 24 & BU 7 KI & & & 22,00 & & 78,00 & Kurang & 147 & 32,34 & Ha Tidak terlayani \\
\hline
\end{tabular}

